\title{
Sinopse de Hibiscus L. (Malvoideae, Malvaceae) do Estado de São Paulo, Brasil: espécies nativas e cultivadas ornamentais
}

\author{
Gerleni Lopes Esteves ${ }^{1,4}$, Marília Cristina Duarte ${ }^{1,2}$ e Cátia Takeuchi ${ }^{3}$
}

Recebido: 6.02.2013; aceito: 15.05.2014

\begin{abstract}
Synopsis of Hibiscus L. (Malvoideae, Malvaceae) in São Paulo State, Brazil: native and ornamental species). This taxonomic treatment of Hibiscus was based on an analysis of more than 100 specimens from herbaria in São Paulo State and of material collected by the authors. The genus is represented by six native species and eight cultivated species for ornamental purposes. The native species are distributed in swampy areas of Atlantic rain forest and Cerrado, while the cultivated species are found in squares, public areas, parks, and private and public gardens. Identification key, illustrations, data on geographic distribution, and comments on morphology and taxonomy of the species are presented. Hibiscus urticifolius A. St.Hil \& Naudin is reported for the first time for São Paulo State.
\end{abstract}

Keywords: flora, geographic distribution, morphology, taxonomy

RESUMO - (Sinopse de Hibiscus L. (Malvoideae, Malvaceae) no Estado de São Paulo, Brasil: espécies nativas e cultivadas ornamentais). O estudo taxonômico das espécies de Hibiscus foi realizado com base no exame de mais de 100 coleções depositadas nos acervos dos herbários do Estado de São Paulo, além de materiais coletados pelas autoras. Foram levantadas 14 espécies (seis nativas e oito cultivadas com fim ornamental). As espécies nativas ocorrem preferencialmente em áreas brejosas nos domínios da Floresta Ombrófila densa e do Cerrado, enquanto que as espécies cultivadas foram encontradas em praças, canteiros públicos, parques, hortos, jardins residenciais e de instituições de pesquisa e ensino. São apresentadas chave de identificação, ilustrações de caracteres diagnósticos, dados de distribuição geográfica e comentários sobre a morfologia e taxonomia das espécies. Hibiscus urticifolius A. St.-Hil. \& Naudin é uma nova ocorrência para o Estado de São Paulo. Palavras-chave: flora, distribuição geográfica, morfologia, taxonomia

\section{Introdução}

Hibiscus, um dos maiores gêneros de Malvaceae, compreende aproximadamente 200 espécies distribuídas nas regiões tropicais e subtropicais e alguns representantes nas regiões temperadas (Fryxell 1997).

O gênero apresenta grande potencial ornamental. No Brasil, várias espécies exóticas são usadas com esse fim, ressaltando-se entre as mais conhecidas: H. rosa-sinensis L. (hibisco, graxa-de-estudante) e H. schizopetalus (Dyer) Hook. f. (hibisco-crespo). Algumas espécies com potencial ornamental, como H. sabdariffa L. e H. acetosella Welw. ex Hiern. são usadas também na alimentação; enquanto outras são empregadas na medicina popular ou como fonte de fibra para a cordoaria (Bates 1965; Lorenzi \& Souza 1995).

Dentre os principais estudos taxonômicos realizados com Hibiscus, destaca-se o de Hochreutiner (1900) no qual foram consideradas 12 seções e 197 espécies, sendo que atualmente são conhecidas mais de 300 espécies (Pfeil \& Crisp 2005). Além disso, ressaltam-se Kearney $(1955,1957)$ que elaborou, com base em dados bibliográficos, chaves de identificação das espécies da América do Norte e América do Sul, respectivamente; Menzel et al. (1983) e Wilson (1993) trataram da taxonomia de Hibiscus seção Furcaria DC.

Outros estudos importantes compreendem inventários florísticos como Rodrigo (1948) para a

1. Instituto de Botânica, Caixa Postal 68041, 01061-970 São Paulo, SP, Brasil

2. Universidade de Mogi das Cruzes, Campus I, Laboratório de Sistemática Vegetal, Av. Dr. Cândido Xavier de Almeida e Souza 200, 08780-911 Mogi das Cruzes, SP, Brasil

3. Programa de Pós-Graduação em Biodiversidade Vegetal e Meio Ambiente, Instituto de Botânica, São Paulo, SP, Brasil

4. Autor para correspondência: gerleniibot@yahoo.com.br 
Flora da Argentina, Robyns (1965) para a Flora do Panamá e os de Fryxell $(1988,1992)$ para as Floras do México e do Equador, respectivamente. Com relação aos estudos mais recentes, além de publicações de espécies novas, ressalta-se a contribuição de Krapovickas \& Fryxell (2004) sobre as espécies sulamericanas.

No que se refere às espécies brasileiras, o estudo de Gürke (1892), na Flora Brasiliensis, continua sendo uma referência importante para o conhecimento do gênero. Além disso, ressaltam-se a citação de espécies que ocorrem no Parque Estadual do Rio Doce, Estado de Minas Gerais (Bovini et al., 2001), no Distrito Federal (Esteves 2001) e a lista publicada no Catálogo de Plantas e Fungos do Brasil (Esteves 2010). Quanto às espécies ornamentais, é importante o estudo de Bates (1965) sobre Malvaceae cultivadas, além do trabalho publicado por Lorenzi \& Souza (1995) que tratou das plantas ornamentais do Brasil, no qual foram mencionadas cinco espécies.

Apesar da sua grande heterogeneidade morfológica, Hibiscus sofreu poucas segregações (Pfeil et al. 2002). As seções estabelecidas para o gênero ainda não foram revisadas em sua totalidade e há ainda muitas espécies que não se enquadram na delimitação das mesmas. As evidências moleculares mostraram que Hibiscus é parafilético, compreendendo espécies de outros gêneros da tribo Hibisceae, bem como gêneros de outras duas tribos de Malvoideae: Malvavisceae e Decaschistieae (Pfeil et al. 2002, Small 2004, Pfeil \& Crisp 2005). De acordo com esses autores, um rearranjo possível compreenderia a criação de um "super" gênero Hibiscus para incluir espécies de tribos distintas. Outra opção seria a segregação de mais de 10 novos gêneros a partir de Hibiscus, ressaltando-se que as duas possibilidades envolveriam numerosas mudanças nomenclaturais, além de um número muito elevado de espécies, incluindo plantas cultivadas.

No presente estudo foi aceita a circunscrição morfológica de Hibiscus adotada por Fryxell (2001) e Krapovickas \& Fryxell (2004), na qual o gênero é caracterizado com base no hábito predominantemente herbáceo a arbustivo, estípulas pequenas não envolvendo os ramos, epicálice constituído de bractéolas livres entre si e gineceu pentacarpelar com cinco estiletes unidos até certa altura e depois livres entre si, com cinco estigmas capitados.

O trabalho representa uma contribuição para o conhecimento das espécies de Hibiscus nativas no Estado de São Paulo, ao mesmo tempo em que trata das espécies cultivadas com fim ornamental, por serem estas bastante usadas como material de pesquisa e de aulas práticas do ensino universitário, demandando muito interesse quanto a sua morfologia e taxonomia.

\section{Material e métodos}

O Estado de São Paulo ocupa uma área de aproximadamente $248.256 \mathrm{~km}^{2}$ na região Sudeste do Brasil. Possui altitudes que variam desde o nível do mar até cerca de $2.800 \mathrm{~m}$ no seu ponto mais alto, a Pedra da Mina, na Serra da Mantiqueira; possui estações úmidas e secas bem definidas e clima do tipo tropical (Eiten 1970, Poçano et al. 1981, SMA 1996, SMA 1998). A vegetação é muito diversificada, compreendendo, principalmente, Florestas Ombrófila densa, Ombrófila mista e Semidecídua, Cerrado, além de outras formações menores, os campos de altitude, as restingas, dunas e manguezais (Coutinho 1978, Veloso et al. 1991, Kronka et al. 2005).

Foram utilizados os procedimentos usuais em estudos taxonômicos, incluindo levantamento bibliográfico, coleta de material e estudo morfológico das espécies. Foram examinadas cerca de 100 exsicatas depositadas nos acervos dos herbários paulistas: BOTU, ESA, IAC, HRCB, SP, SPF, SPFR, UEC e PMSP (siglas segundo Thiers 2012) e coleções oriundas de coletas realizadas pelas autoras. A coleta de material das espécies cultivadas foi realizada em áreas públicas (praças, canteiros, parques) e privadas (jardins residenciais e de instituições de ensino e pesquisa).

Nas descrições dos táxons foram utilizadas as terminologias propostas por Houchretiner (1900) e Krapovickas \& Fryxell (2004). As informações sobre a distribuição geográfica de cada táxon correspondem a sua amplitude global; enquanto as referências de nomes populares e dados de morfologia e de épocas de floração e frutificação são baseadas no material examinado. As ilustrações foram feitas pelas autoras com auxílio de estereomicroscópio acoplado a câmara clara e cobertas a nanquim pelo ilustrador Klei Souza pela Emiko Naruto.

\section{Resultados e Discussão}

Hibiscus L., Sp. pl.: 693. 1753, nom. cons.

Subarbustos a arbustos, raramente arvoretas, aculeados ou não. Folhas com lâminas inteiras, lobadas a partidas, sem ou com 1-5 nectários sobre as nervuras na face abaxial; estípulas não envolvendo 
os ramos. Flores axilares, solitárias ou em fascículos, ocasionalmente agrupadas no ápice de ramos axilares; epicálice presente, bractéolas livres entre si, inteiras ou 2-lobadas no terço apical, menores ou maiores que o cálice; cálice simétrico, acrescente e persistente no fruto, em geral com 1 nectário sobre as nervuras principais; pétalas diversamente coloridas, às vezes com mancha basal; tubo estaminal 5-denteado no ápice, partes livres de estames numerosas; ovário 5-carpelar, 5-locular, lóculos multiovulados, estiletes 5, unidos até certa altura e depois livres entre si, estigmas capitados. Fruto cápsula loculicida, geralmente globosa, glabrescente; sementes numerosas, em geral obovóides.

O gênero está representado no Estado de São Paulo por seis espécies nativas e oito espécies cultivadas.

Chave para as espécies de Hibiscus do Estado de São Paulo

1. Plantas com acúleos

2. Lâminas foliares inteiras a 3-5-lobadas; pétalas róseas com mancha basal vinácea; sementes sem escamas pectinadas

3. Epicálice maior que o cálice; bractéolas 2-lobadas no terço apical 1. H. bifurcatus

3. Epicálice menor que o cálice; bractéolas inteiras 2. H. diversifolius

2. Lâminas foliares 3-7-partidas; pétalas amarelas, arroxeadas a avermelhadas, sem ou com mancha basal vinácea; sementes com escamas pectinadas

4. Folhas e cálice sem nectários 9. H. radiatus

4. Folhas e cálice com nectários 8. H. cannabinus

1. Plantas sem acúleos

5. Bractéolas do epicálice 2-lobadas no terço apical

6. Lâminas foliares com 1 nectário, às vezes inconspícuo; ramos quase glabros ou com tricomas estrelados diminutos, adensados; cápsulas com indumento de tricomas estrelados e/ou simples, curtamente rostrada, rostros 1-2 mm compr.

7. Plantas vermelhas a vináceas, raramente verdes; lâminas foliares crenadas na margem; cápsula apenas com tricomas simples adpressos; sementes recobertas de escamas pectinadas

7. H. acetosella

7. Plantas verdes; lâminas foliares serreadas na margem; cápsula com tricomas simples e estrelados; sementes lisas 3. H. furcellatus

6. Lâminas foliares com (1-)3(-5) nectários; ramos com tricomas estrelados grandes associados com longos tricomas simples híspidos, patentes; cápsulas glabra; longamente rostradas, rostros 3-6 mm compr.

4. H. kitaibelifolius

5. Bractéolas do epicálice inteiras, não lobadas

8. Cálice vermelho, carnoso, com 1 nectário sobre cada uma das nervuras principais; lâminas foliares com nectário na face abaxial; pétalas amarelas

8. Cálice verde, não carnoso, sem nectários 6. H. sabdariffa

9. Tubo estaminal maior que as pétalas; cálice quase glabro

10. Flores pêndulas, pétalas reflexas, profundamente laceradas; pedicelos maiores que as lâminas foliares 11.H. schizopetalus

10. Flores suberetas; pétalas eretas, inteiras ou levemente laceradas no ápice; pedicelos menores que as lâminas foliares 10. H. rosa-sinensis

9. Tubo estaminal menor que as pétalas; cálice piloso

11. Bractéolas do epicálice diferenciadas morfologicamente, com a porção basal alongada, linear e a porção apical dilatada, reniforme 6. H. sororius

11. Bractéolas do epicálice lineares, sem diferenciação morfológica 12. Lâminas foliares obovadas, de contorno rômbico, com nectário 13. H. syriacus 12. Lâminas foliares ovadas, sem nectários

13. Lâminas foliares inteiras, estreitamente ovadas 5. H. urticifolius

13. Lâminas foliares 3-7-lobadas, largamente ovadas 8. H. mutabilis 
1. Hibiscus bifurcatus Cav., Diss. 3: 146, tab. 51, fig.1. 1787.

Nome popular: algodão-do-brejo

Figura 1g-h

Dentre as espécies nativas no Estado de São Paulo, Hibiscus bifurcatus e $H$. diversifolius são as únicas que apresentam acúleos, mas podem ser facilmente distintas pela primeira espécie apresentar as bractéolas do epicálice bilobadas no terço apical, enquanto que a segunda tem as bractéolas inteiras.

Hibiscus bifurcatus possui os ramos com acúleos curtos e muito próximos entre si, associados com tricomas simples híspidos e geralmente retrorsos. A corola (até $10 \mathrm{~cm}$ compr.) é sempre rosada com mancha basal vinácea e o tubo estaminal é inserto. Um caráter distinto nessa espécie é a presença de tufos de tricomas adpressos esparsos nas sementes.

A espécie distribui-se desde a América Central, estendendo-se pelas Antilhas, Norte da América do Sul até as regiões Norte, Nordeste e Sudeste do Brasil (PA, AP, AC, BA, MG, RJ, SP). No Estado de São Paulo foi encontrada em áreas brejosas do litoral, no domínio da Floresta Ombrófila densa.

Material examinado: BRASIL. São PAUlo: Guarujá, Ilha de Santo Amaro, III-1951, B. Pickel s.n. (SPSF4144); Itanhaém, IX-2005, R.J.F. Garcia 2582 \& F.R. Branco (PMSP); Praia Grande, V-1946, A.B. Jolly s.n. (SPF17302); São Vicente, IX-2001, J.A. Pastore \& C. Moura 1199 (SPSF); Santos, Praia de São Lourenço, IV-1966, J. Mattos 13569 (SP); Ubatuba, Parque Estadual da Serra do Mar, Núcleo Picinguaba, IX-2004, J.R. Guillaumon s.n. (SPSF43095, SP).

2. Hibiscus diversifolius Jacq., Collectania 2:307. 1788 [1789].

Figura 1i

Hibiscus diversifolius compartilha com $H$. urticifolius e $H$. sororius o epicálice formado por bractéolas inteiras e a corola rosada a arroxeada com o tubo estaminal incluso; porém distingue-se, principalmente, por possuir as folhas pentalobadas, com um nectário sobre a nervura média na face abaxial (vs. inteiras e sem nectário) e o cálice com tricomas simples, apresentando um nectário oblongo sobre as nervuras principais (vs. tricomas estrelados e sem nectário). Cápsula apiculada, com sementes lisas e glabras.

A espécie está distribuída na África, América Central e América do Sul. No Brasil ocorre nos
Estados de São Paulo, Paraná e Santa Catarina. No Estado de São Paulo foi encontrada em Floresta Ombrófila densa, nas margens de brejos.

Material selecionado: BRASIL. São PaUlo: Lorena, XI-1939, M. Kuhlmann \& A. Gehrt s.n. (SP40269); São Paulo, III-1934, W. Hoehne s.n. (SPF11183); São Paulo, II-1935, s.c. (SP32305); Taubaté, IV-1928, F.B. Junior s.n. (SP22514).

3. Hibiscus furcellatus Lam., Encycl. 3:358, 1789. Figura $1 \mathrm{j}$

Hibiscus furcellatus é um arbusto não aculeado (1,5-4 m alt.), com os ramos recobertos de indumento denso de tricomas estrelados diminutos e folhas de lâminas inteiras a trilobadas com um nectário sobre a nervura média. A semelhança de outras espécies possui as cápsulas rostradas, porém com o rostro comparativamente muito curto (1-2 mm compr.). As sementes são lisas e glabras.

Ocorre desde América do Norte e América Central, estendendo-se pelas Antilhas, até o Brasil (AM, AP, PA, RO, TO, AL, BA, MA, PB, PI, MS, MT, ES, MG, SP e PR) e Paraguai. No Estado de São Paulo foi encontrada em Floresta Ombrófila densa e áreas de restinga, na margem de brejo e de mata ciliar. Flores e frutos em outubro e novembro.

Material examinado: BRASIL. São PAULo: Presidente Epitácio, Reserva Estadual Lagoa São Paulo, XI-1992, I. Cordeiro et al. 1128 (SP); Sul do Estado de São Paulo, margem do Rio Paraná, X-1998, L.R.H. Bicudo et al. 257 (BOTU, SP); Ubatuba, IV-2001, R.M.R. Duarte s.n. (SPSF32754).

4. Hibiscus kitaibelifolius A.St.-Hil., Fl. bras. mer. [folio ed.] 1: 193, t.48. 1825.

Figura 1a-f

Hibiscus kitaibelifolius compartilha com outras espécies que ocorrem no Estado de São Paulo a ausência de acúleos e as bractéolas do epicálice bilobadas no terço apical. Em relação a essas espécies, H. kitaibelifolius é claramente distinta por ser a única a apresentar as lâminas com três a sete lobos, tendo um a três, raramente cinco, nectários sobre as nervuras principais na face abaxial. Destaca-se também pela cápsula glabra e longamente rostrada, com o rostro atingindo até $5 \mathrm{~mm}$ de comprimento. $\mathrm{O}$ indumento nessa espécie também ajuda no seu reconhecimento por ser amarelado e constituído de tricomas estrelados grandes e longos tricomas simples híspidos. 
Endêmica do Brasil, com distribuição nos Estados de Minas Gerais e São Paulo. Neste último, ocorre preferencialmente em Cerrado e Floresta Ombrófila densa, em áreas brejosas e na margem de córregos.

Material selecionado: BRASIL. SÃo PAULO: Itirapina, II-1985, F.R. Martins 16861 (UEC); Pariquera-AçuRegistro, X-1970, H.F. Leitão Filho 107 (IAC); Pinheiros, IV-1927, A. Gehrt s.n. (SP19750); Registro,
VII-1965, C. Moura s.n. (SP130309); São Paulo, III-1931, Vizioli s.n. (SP27259); São Paulo, V-1933, W. Hoehne s.n. (SPF10002); São Paulo, V-1934, F.C. Hoehne s.n. (SP31767); São Paulo, Santo Amaro, XI-1943, Rotti 421 (SP); São Paulo, Itaquera, V-1993, L. Rossi 1362 (SP); São Paulo, Parque Ecológico da APA do Carmo, $23^{\circ} 35^{\prime} \mathrm{S}, 46^{\circ} 28^{\prime} \mathrm{W}, \mathrm{V}-1994$, S.A.P. Godoy et al. 174 (HRCB, SP, SPF, UEC, PMSP);

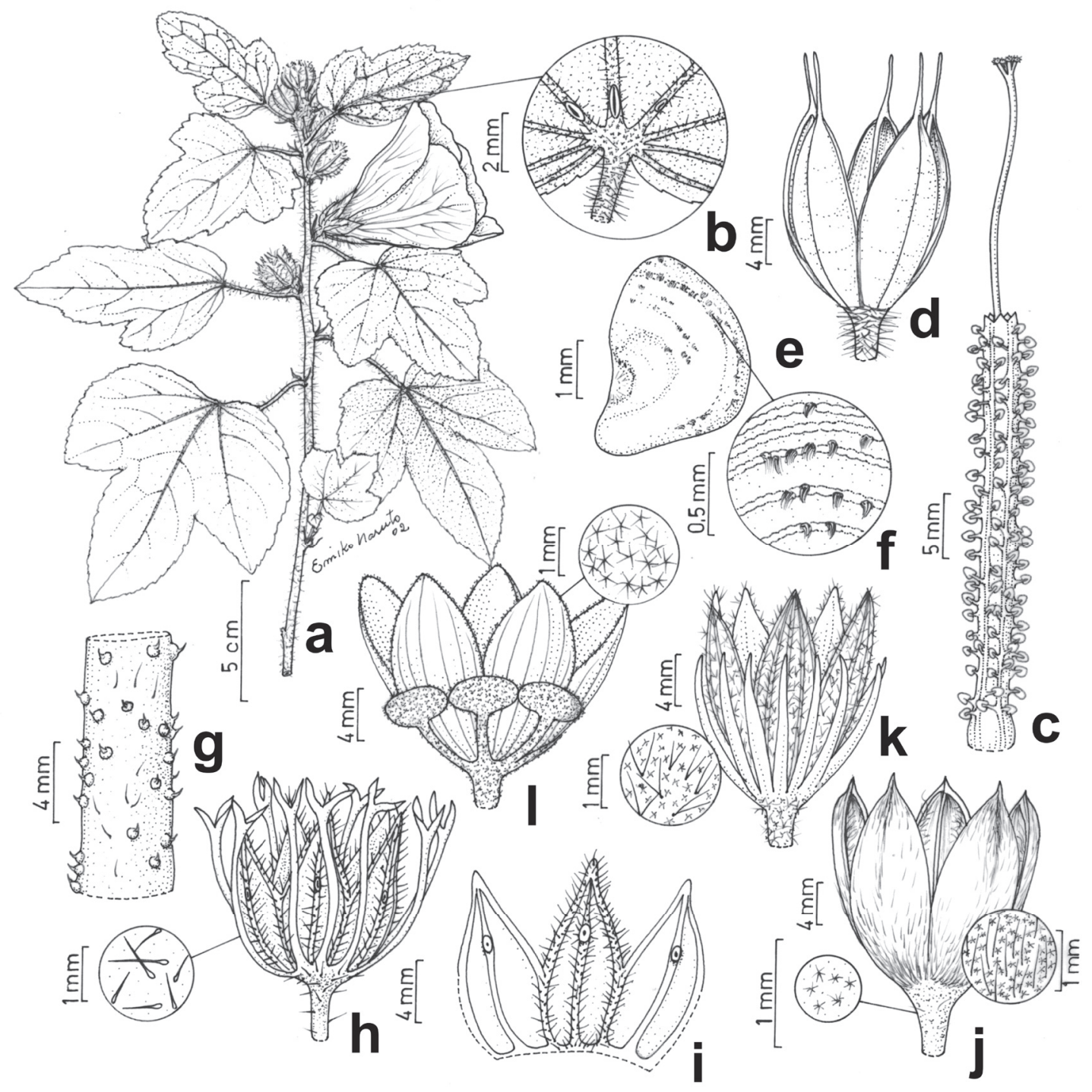

Figura 1. Espécies de Hibiscus do Estado de São Paulo, Brasil. a-f. H. kitaibelifolius. a. Ramo com flores. b. Parte da lâmina foliar, face abaxial, mostrando os nectários. c. Tubo estaminal. d. Cápsula. e. Semente, vista látero-dorsal. f. Detalhe da semente mostrando as escamas pectinadas. g-h. H. bifurcatus. g. Parte do ramo, mostrando os acúleos e tricomas. h. Cálice e epicálice, com detalhe do indumento do epicálice. i. H. diversifolius. Parte do cálice, face externa. j. H. furcellatus. Cápsula e detalhe do indumento. k. H. urticifolius. Cálice e epicálice, com detalhe do indumento do epicálice. 1. H. sororius. Cálice e epicálice, com detalhe do indumento do cálice.

Figure 1. Species of Hibiscus in the São Paulo State, Brazil. a-f. H. kitaibelifolius. a. Branch with flowers. b. Part of leaf blade, showing the nectaries. c. Staminal tube. d. Capsule. e. Seed, dorsolateral view. f. Detail of seed showing the pectinate scales. g-h. H. bifurcatus. g. Part of branch, showing the prickles and trichomes. h. Calyx and epicalyx, with detail of indumentum on the epicalyx. i. H. diversifolius. Part of calyx, external face. j. H. furcellatus. Capsule and detail of indumentum. 1. H. sororius. Calyx and epicalyx, with detail of indumentum on the calyx. 
Tremembé, I-1929, I. Tibiriçá s.n. (SP23628); Pindamonhangaba, VII-2009, C. Takeuchi \& G.L. Esteves 61 (SP).

5. Hibiscus urticifolius A. St.-Hil. \& Naudin. Ann. Sci. Nat., Bot., sér. 2, 18: 39. 1842.

Figura 1k

Os principais caracteres diagnósticos estão no cálice: o comprimento sempre maior que o do epicálice, o indumento constituído de tricomas estrelados pequenos e grandes, estes últimos híspidos e a ausência de nectários. As lâminas são invariavelmente inteiras, estreitamente ovadas, discolores e sem nectários e as flores grandes $($ ca. $9 \mathrm{~cm})$ possuem as pétalas arroxeadas.

Ocorre na Bolívia, Brasil, Paraguai, Argentina e Uruguai. No Brasil possui distribuição do Estado de São Paulo até o do Rio Grande do Sul. Trata-se da primeira citação da espécie para o Estado de São Paulo, onde é conhecida apenas por dois materiais antigos oriundos de margem de rios e terrenos brejosos no domínio do Cerrado.

Material examinado: BRASIL. SÃo Paulo: Moji Guaçu, X-1955, M. Kulhmann 3703 (SP); Paulínea, XI-1956, A.S. Grottz s.n. (SP119683).

6. Hibiscus sororius L., Pl. Surin. 12. 1775. Figura 11

Trata-se da única espécie que ocorre no Estado de São Paulo a apresentar as bractéolas do epicálice alongadas e lineares na parte basal, dilatadas e reniformes na parte apical (figura 11). Outros caracteres que auxiliam no seu reconhecimento são o indumento amarelado, constituído de tricomas estrelados muito pequenos e adpressos e as cápsulas globosas, múticas e nigrescentes.

A espécie tem distribuição neotropical. $\mathrm{Na}$ América do Sul ocorre na Bolívia, Brasil (AC, AM, MS, MT, MG, SP e PR) e Argentina. No Estado de São Paulo foi encontrada em Floresta Estacional Semidecídua, em locais brejosos.

Material examinado: BRASIL. SÃo Paulo: Gália, Parque Estadual de Caetetus, $22^{\circ} 20^{\prime}-22^{\circ} 26^{\prime} \mathrm{N}, 49^{\circ} 40^{\prime}-$ 4944'L, III-1981, C.F S. Muniz 358 (SP).

Material adicional examinado: BRASIL. AMAZONAS: s.1., VIII-1991, S. Mori \& C. Gracie 21761 (SPF). Mato Grosso: Garapú, 1312'S, 52³4'W, IX-1964, H.S. Irwin \& T.R. Soderstrom 6448 (SP). Мато
Grosso do Sul: Anaurilândia, 22²3'11"S, 5252'4"W, X-1998, A. Amaral Jr. et al. 261 (BOTU, SP).

7. Hibiscus acetosella Welw. ex Hiern., Cat. Afr. pl. 1:73. 1896.

Nomes populares: vinagreira, guaxima-de-jardim, groselheira

Figura $2 \mathrm{~d}-\mathrm{h}$

Além da ausência de acúleos nos ramos e da coloração das plantas geralmente vermelha a vinácea, essa espécie caracteriza-se com base na morfologia das folhas, pelas lâminas variando de inteiras a 3-5-lobadas, com margem crenada e base truncada a cuneada, apresentando um nectário sobre a nervura média, na face abaxial. As bractéolas do epicálice são bilobadas no terço apical como em outras espécies do gênero, porém em $H$. acetosella os lobos possuem comprimentos distintos. Com relação à cápsula, destaca-se por ser maior que o cálice, recoberta de tricomas simples antrosos e adpressos e as sementes com escamas pectinadas esparsas.

Nativa da África, provavelmente de Angola, cultivada no mundo todo com fim ornamental. No Estado de São Paulo foi encontrada principalmente em parques, hortos e canteiros públicos. Em Angola é utilizada na alimentação do homem, pelas folhas de sabor ácido, daí o nome popular de vinagreira, apreciadas como salada (Bates 1965; Krapovickas \& Fryxell 2004). Flores e frutos o ano todo.

Material selecionado: BRASIL. São PaUlo: Campinas, Campo Experimental do Instituto de Campinas, X-1939, O. Kriegel s.n. (IAC4820, SP43505); Itanhaém, Jardim Ivoty, V-1997, I. Cordeiro 1647 (SP); Piracicaba, Horto do Departamento de Botânica ESA \USP, V-1989, D. Biserka \& K. Duarte s.n. (ESA4159); Piracicaba, Campos da ESALQ, IX-1993, K.D. Barretos et al. 1179 (ESA); São Paulo, Horto da Faculdade de Farmácia, V-1949, W. Hoehne s.n. (SPF12429, SP321236, UEC106722); São Paulo, Parque do Estado, V-1971, L. Rodrigues 58 (SP117370); São Paulo, Cidade Jardim, VIII-1934, W. Hoehne s.n. (SP32212); São Paulo, Jardim Botânico, VI-1931, F.C. Hoenhe 273 (SP); São Paulo, Ibirapuera, VI-1987, P. Bahia s.n. (PMSP1415); São Paulo, Parque do Ibirapuera, Viveiro Manequinho Lopes, V-2001, C.M. Izumisawa 303 \& C.G. Moreira (PMSP); São Paulo, Parque do Ibirapuera, Viveiro Manequinho Lopes, V-2009, G.L. Esteves \& Takeuchi 2801 (SP). Tremembé, X-1944, B.J. Pickel (SPSF919); Tremembé, V-1939, B.J. Pickel 4348 (SP). 
8. Hibiscus mutabilis L., Sp. pl.: 694. 1753.

Nomes populares: papoula-de-duas-cores, rosa-louca, rosa-paulista, inconstante, amor-de-

homem

Figura 2 a-c

Esta espécie compartilha com outras espécies cultivadas no Estado de São Paulo as bractéolas do epicálice lineares e a ausência de acúleos e nectários nas folhas e no cálice. Entretanto, é perfeitamente distinta pelas lâminas foliares comparativamente muito grandes, atingindo até $33 \mathrm{~cm}$ de comprimento, largamente ovadas de base cordada e margem crenadoserreada, apresentando 5-7 lobos triangulares. As pétalas simples ou dobradas variam de amarelas a alvas, tornando-se rosadas quando velhas, daí os nomes populares da espécie que fazem referência às mudanças de coloração da corola. Dentre as espécies cultivadas, distingue-se também pelas cápsulas globosas e múticas e pelas sementes hirsutas na parede oposta ao hilo. Vale ressaltar também que se trata de uma espécie com hábito arbustivo a arbóreo, podendo atingir até 5 metros de altura.

Provavelmente nativa da China, amplamente cultivada nas regiões tropicais e subtropicais. No Estado de São Paulo é cultivada principalmente em jardins residenciais, canteiros e vias públicas. Flores e frutos o ano todo.

Material selecionado: BRASIL. São PAULo: Araçatuba, IV-1944, H. Bittencourt s.n. (IAC7297); Campinas, II-1949, C. Pacheco s.n. (IAC10391); Caraguatatuba, XI-1956, H.M. Souza s.n. (IAC18286); São Paulo, Santo Amaro, IV-1992, J.A. Pastore 420 (SPSF); São Paulo, Água Funda, canteiro público à margem da Rodovia dos Bandeirantes, V-2008, G.L. Esteves \& M.C. Duarte 2806 (SP) São Paulo, Parque Vila dos Remédios, IV-1987, S. Honda \& V.C. Souza 855 (PMSP); São Paulo, Marsilac, VI-2003, H. Ogata et al. s.n. (PMSP7407); São Paulo, V-2009, Vila Sônia, C. Takeuchi 58 (SP); São Paulo, zona leste, III-2006, S. Aguiar 03 (SP). Sorocaba, III-1945, B.J. Pickel s.n. (SPSF1172); Tremembé, V-1952, B.J. Pickel s.n. (SPSF4260); Ubatuba, jardim residencial, IX-1938, A.P. Viegas \& A.S. Costa s.n. (IAC3989).

9. Hibiscus radiatus Cav., Diss. 3: 150, t. 54, f. 2. 1787.

Nomes populares: cânhamo-brasileiro, madrugada, papoula-do-são-francisco

Figura $2 \mathrm{k}-\mathrm{m}$

Espécie distinta pelos acúleos muito pequenos com cerca de $1 \mathrm{~mm}$ compr., retrorsos e esparsos entre si. Outros caracteres marcantes são: as lâminas (4-)5-7-partidas, sem nectários; cálice sem nectários, externamente com tricomas simples híspidos amarelados e as pétalas roxo-avermelhadas. Um caráter que varia apenas nessa espécie diz respeito às bractéolas do epicálice que podem ser inteiras ou bifurcadas na porção apical em espécimes de um mesmo indivíduo. Em coleções de herbário é geralmente confundida com $H$. cannabinus L. (ver os comentários desta última).

Provavelmente nativa da Ásia tropical, amplamente cultivada com fins ornamentais e ocasionalmente como fonte de fibra.

Material selecionado: BRASIL. São PAULO: Campinas, IV-976, N. Taroda s.n. (UEC4173); Campinas, Instituto Agronômico de Campinas, V-1939, M. Meneghini s.n. (SP40094, IAC); Campinas, III-1940, O. Kriegel s.n. (IAC5406, SP43510); Campinas, Fazenda Santa Elisa, IV-1948, D. Dedecca s.n. (IAC9304); Limeira, IV-1934, A. Gehrt s.n. (SP48229); Mogi-Mirim, V-1927, F.C. Hoehne s.n. (SP20512); Pindorama, III-1939, G.P. Viegas s.n. (IAC5129, SP43506); São Paulo, Parque do Estado, III-1944, W. Hoehne s.n. (SP321168; SPF11182); São Paulo, V-1934, s.c. (SP31765); São Bernardo, II-1937, J. Carneiro s.n. (SP37786); Sorocaba, III-1945, B.J. Pickel s.n. (SPSF1172); Ubatuba, IX-1938, A.P. Viegas \& A.S. Costa s.n. (IAC3989); Tremembé, VI-1928, J. Sampaio 350 (SP).

10. Hibiscus rosa-sinensis L., Sp. pl. 694. 1753.

Nomes populares: mimo-de-vênus, papoula, hibiscusgraxa, graxa-de-estudante, graxa-de-soldado, limpasapato

Figura $2 \mathrm{r}$

Esta espécie assemelha-se a H. schizopetalus cuja identidade é considerada como espécie distinta ou como variedade de $H$. rosa-sinensis. As principais diferenças entre as duas espécies estão na morfologia floral, principalmente na posição das flores, geralmente ereta em H. rosa-sinensis e pêndula em H. schizopetalus, coloração das pétalas (rosada a vermelha com mancha basal vs. vermelhas e sem mancha), tipo de limbo das pétalas (inteiro ou lacerado no ápice vs. profundamente lacerado em toda a extensão) e no comprimento do pedicelo, sempre maior em $H$. schizopetalus.

Provavelmente nativa da China. Trata-se de uma espécie amplamente cultivada no Brasil pela beleza de suas flores e por ter crescimento rápido. No Estado de São Paulo é a espécie mais cultivada com 


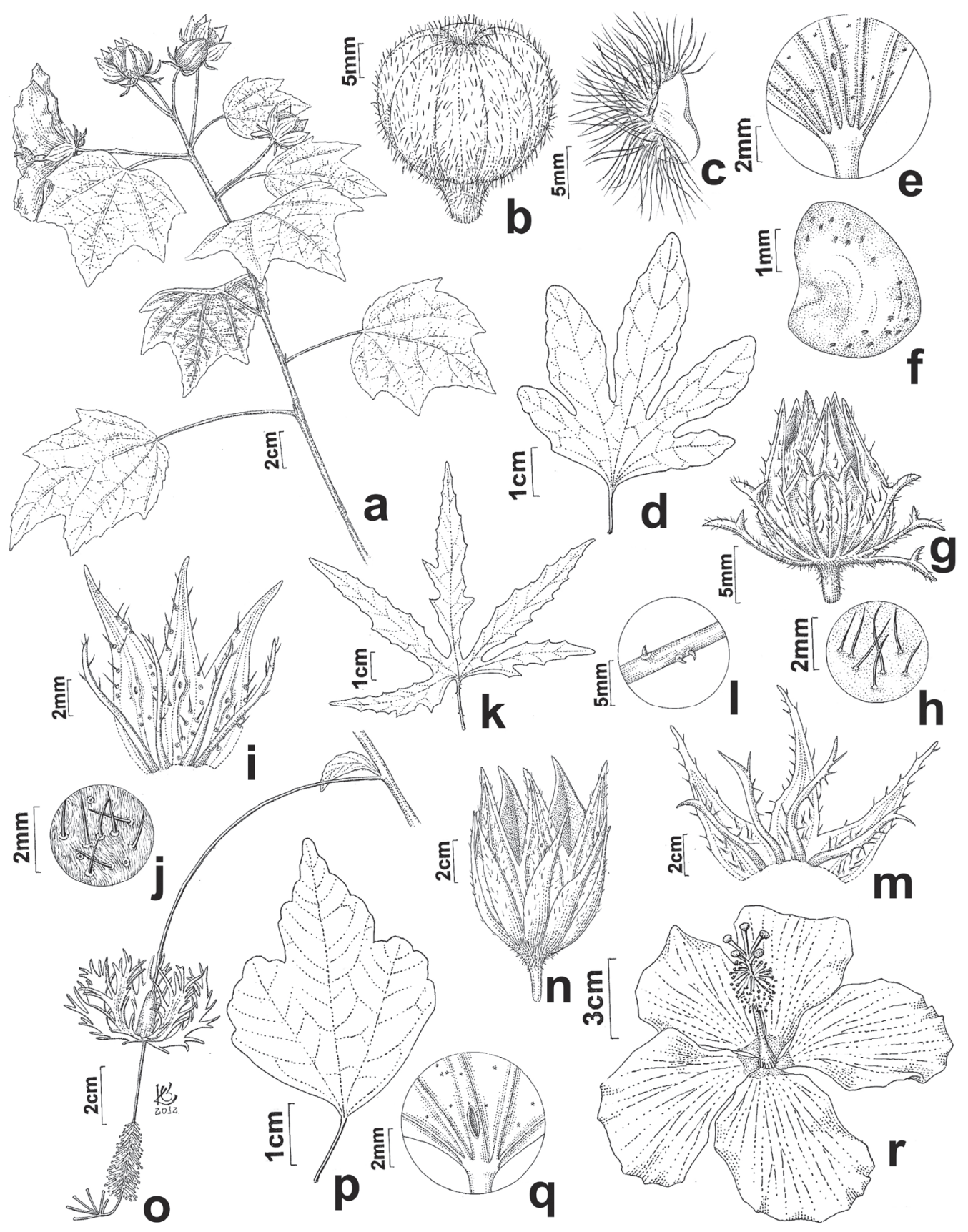

Figura 2. Espécies de Hibiscus do Estado de São Paulo, Brasil. a-c. H. mutabilis. a. Ramo com flores. b. cápsula. c. semente. d-h: H. acetocella. d. folha, face adaxial. e. Parte da folha, mostrando o nectário na face abaxial. f. Semente, vista látero-dorsal, mostrando as escamas pectinadas. g. Cálice e epicálice envolvendo o fruto. h. Detalhe dos tricomas do cálice. i-j. H. cannabinus. i. Parte do cálice e do epicálice, superfície externa. j. Detalhe dos tricomas do cálice. k-m. H. radiatus. k. Folha, face abaxial. 1. Detalhe dos acúleos dos pecíolos. m. Parte do cálice e do epicálice, superfície externa. n. H. sabdariffa. cálice e epicálice. o. H. schizopetalus. Ramo com flor. p-q. H. syriacus. p. Folha, face adaxial. q. Detalhe do nectário sobre a nervura média, face abaxial da lâmina. r. H. rosa-sinensis, flor mostrando a corola e o tubo estaminal no centro.

Figure 2. Species of Hibiscus in São Paulo State, Brasil. a-c. H. mutabilis. a. Branch with flowers. b. Capsule. c. Seed. d-h. H. acetocella. d. Leaf blade, adaxial face. e. Part of leaf blade, showing the nectary on the adaxial face. f. Seed, dorsolateral view, showing the pectinate scales. g. Calyx and epicalyx involving the fruit. h. Detail of trichomes on the calyx. i-j. H. cannabinus. i. Part of calyx and epicalyx, external surface. j. Detail of trichomes on the calyx. k-m. H. radiatus. k. Leaf blade, abaxial face. 1. Detail of prickles on the petioles. m. Part of epicalyx and calyx, external surface. n. H. sabdariffa. Calyx and epicalyx. o. H. schizopetalus. Branch with flower. H. syriacus. p. Leaf blade, adaxial face. q. Detail of nectaries on the median rib, leaf adaxial face. r. H. rosa-sinensis. Flower showing the corolla and the staminal tube in the center. 
fim ornamental tanto em lugares públicos como em privados, especialmente na arborização urbana e em jardins públicos e residenciais de forma isolada ou como cerca viva. Possui diversos híbridos, variedades e formas com flores morfologicamente distintas, especialmente no que se refere ao tamanho, coloração e organização da corola constituída de pétalas simples ou dobradas.

Material selecionado: BRASIL. S̃̃o PAULO: Campinas, Instituto de Química da UNICAMP, X-1990, P. Bonesso 1 (UEC); Campinas, Barão Geraldo, V-1982, D.A.S. Oliveira 13.657 (UEC); Campinas, Parque do Instituto Agronômico, III-1944, J. Santoro s.n. (SP 1804); Cotia, Bairro Caputera, IV-2009, V.M. Gonçalez 30 (SP); Ribeirão Preto, Praça pública, III-1978, L.A. Cardone 1 (SP); São Paulo, IX-1947, B.J. Pickel s.n. (SPSF3073); São Paulo, Instituto de Botânica, IV-1966, B.V. Skvortzov 9 (SP); São Paulo, Vila Mariana, jardim residencial, VI-2000, H.O. Ferraz 5 (SP); São Paulo, Morumbi, X-198, V.C. Souza et al. s.n. (PMSP1072); São Paulo, Butantã, II-2002, C.P. Faria s.n. (PMSP6736); São Paulo, Parque do Ibirapuera, Viveiro Manequinho Lopes, V-2009, G.L. Esteves \& C. Takeuchi 2799 (SP); São Paulo., Avenida Jabaquara, próximo ao metrô São Judas, III-2009, C. Takeuchi 52 (SP); São Paulo, Vila Sônia, V-2009, C. Takeuchi 57 (SP). Serra Negra, Praça Sesquicentenário, VI-1993, C. Aranha \& C.Y. Aranha 1015 (IAC, SP).

11. Hibiscus schizopetalus (Dyer) Hook. f., Bot. Mag.: 106, t. 6524. 1880.

Nomes populares: lanterna-japonesa, paraqueda, hibisco-crespo

Figura 20

Hibiscus schizopetalus é facilmente reconhecida pelas flores solitárias, pêndulas com as pétalas reflexas, inteiramente vermelhas e profundamente laceradas com o limbo formando segmentos lineares. Outro caráter marcante nessa espécie é o tubo estaminal longamente exserto e pendente, com as partes livres dos estames concentradas na sua porção apical. Tal como $H$. rosa-sinensis, também não produz fruto com frequência, sendo propagada vegetativamente. Em poucos exemplares foram examinadas cápsulas múticas, apresentando externamente raros tricomas estrelados e simples diminutos.

Origem no leste da África, cultivada no mundo todo com fim ornamental, sendo muito utilizada em cercas vivas. Depois de H. rosa-sinensis, é a espécie mais cultivada no Estado de São Paulo com fim ornamental.
Material selecionado: BRASIL. São PAULO: Campinas, VII-2005, E. Ikemoton 05/39 (UEC 144749); Limeira, X-1939, H.P. Krug \& O. Zagatto s.n. (IAC5350); Piracicaba, X-1943, C. Texeira s.n. (IAC7334); Rio Claro, II-1985, F.S. Torres s.n. (HRCB4993); Rio Claro, 1968, G. Marinis s.n. (IAC24043); São Paulo, IV-1949, B.J. Pickel s.n. (SPSF3719). São Paulo, Parque do Ibirapuera, I-1985, I. Soares s.n. (PMSP510); São Paulo, Parque do Ibirapuera, Viveiro Manequinho Lopes, V-2009, G.L. Esteves \& C. Takeuchi 2800 (SP).

12. Hibiscus sabdariffa L., Sp. pl. 695. 1753, nom. cons.

Nomes populares: quiabo-roxo, caruru-azedo, groselheira

Figura $2 \mathrm{n}$

Trata-se de uma espécie de fácil reconhecimento pelo cálice e epicálice carnosos de coloração vermelha até vinácea, muito utilizada na fabricação de vinho e geléia. Os ramos, nessa espécie, são vináceos, raramente apresentam acúleos cônicos esparsos entre si e as folhas, também vináceas, possuem as lâminas tri a pentapartidas tendo um nectário sobre nervura média na face adaxial. Quanto aos caracteres florais destacam-se ainda as pétalas amareladas e o tubo estaminal inserto na corola.

Provavelmente de origem africana. Amplamente cultivada em várias partes do mundo com fim alimentício. Menos comumente é cultivada como fins ornamentais, medicinais ou industriais (fibras). Conhecida em outros Estados brasileiros como quiabo-de-angola, azedinha, carurú, caruru-da-guiné (MG), reselha (BA) e vinagreira (PA, CE, ES).

Material selecionado: BRASIL. SÃo PAUlo: Campinas, V-1936, A. Carvalho s.n. (IAC525); Campinas, IV-1940, O. Zagatto s.n. (IAC5499); Campinas, V-1995, L.C. Bernacci \& G.S. Giomo 59 (IAC); São Paulo, Horto Florestal, X-1945, R.M. Alvarenga s.n. (SPSF2325); São Paulo, IV-1949, L. Assis s.n. (SPSF3289); São Paulo, Parque do Ibirapuera, Viveiro Manequinho Lopes, V-2001, C.M. Izumisawa \& $R$. Peña 307 (PMSP).

13. Hibiscus syriacus L., Sp. pl. 695. 1753.

Nomes populares: rosa-da-síria, mimo-de-venus, hibisco-branco

Figura $2 \mathrm{p}-\mathrm{q}$

$\mathrm{Na}$ morfologia das folhas estão os principais caracteres que facilitam o reconhecimento dessa espécie, destacando-se as lâminas inteiras a trilobadas, 
obovadas de contorno rômbico, com base cuneada e margem crenada na porção apical e inteira na porção basal, com 1(-2) nectários sobre a nervura média. Trata-se de uma arvoreta que pode atingir até 6 metros de altura. A coloração das pétalas varia de alvas, rosadas a lilases. Nos materiais do Estado de São Paulo não foram observadas pétalas dobradas conforme mencionado por Bates (1965).

Nativa da China. Amplamente cultivada, especialmente junto de muros ou cercas, podendo atingir até $3 \mathrm{~m}$ de altura.

Material selecionado: BRASIL. SÃo PAULO: Piracicaba, XI-1994, E.C. Sobrinho 1 (ESA); Santos, Orquidário Municipal, XII-1988, V.C. Souza 427 (ESA); São Paulo, XII-1945, B.J. Pickel s.n. (SPSF1324); São Paulo, Parque do Ibirapuera, XII-1987, M.O. Pedraz et al. s.n. (PMSP1204); São Paulo, Largo da Batalha, I-1985, I. Soares s.n. (PMSP482); São Paulo, Vila Mariana, jardim residencial, 2010, G.L. Esteves 2805 (SP).

14. Hibiscus cannabinus L., Syst. Nat. ed. 10, 2: 1149. 1759

Nomes populares: cânhamo-brasileiro, papoula-dosão-francisco

Figura $2 \mathrm{i}-\mathrm{j}$

Espécie geralmente confundida com $H$. radiatus com base nos caracteres vegetativos, especialmente por ambas compartilharem os ramos aculeados e as lâminas foliares partidas em três a seis segmentos, sendo estes de ápice agudo a cuspidado, base truncada a cuneada e margem esparsamente serreada. Entretanto, com relação aos caracteres florais as duas espécies são bastante distintas, sobretudo por H. canabinnus apresentar o cálice recoberto por indumento lanuginoso esbranquiçado associado com tricomas simples híspidos de base espessada, esparsos e decíduos. Além disso, o cálice nessa espécie possui nectários sobre as nervuras principais e cicatrizes vináceas dos tricomas decíduos, dispersas em toda a superfície. Quanto à coloração das pétalas, $H$. cannabinus tem pétalas amarelas a vináceas, enquanto $H$. radiatus tem roxas a avermelhadas.

Essa espécie tem origem africana, difundida nos trópicos e subtrópicos, onde é cultivada principalmente como fonte de fibra e por suas folhas e flores comestíveis e sementes oleaginosas. Ocasionalmente é usada como ornamental.

Material selecionado: BRASIL. SÃo PAULO: Campinas, Fazenda Santa Elisa, IV-1948, D. Dedecca s.n.
(IAC9306); Campinas, Fazenda Santa Elisa, IV-1948, D. Dedecca s.n. (IAC 9307); São Paulo, Cantareira, Horto da Seção de Fitopatologia, I-1932, s.c. (SP28704); Ubatuba, jardim residencial, V-2009, $L$. Cordi \& B.H.P. Rosado 12 (UEC).

\section{Agradecimentos}

Aos curadores dos herbários visitados; ao Klei Souza e Emiko Naruto, pela cobertura dos desenhos a nanquim; ao Victor M. Gonçalez, pela participação nas coletas e leitura do manuscrito.

\section{Literatura citada}

Bates, D.M. 1965. Notes on the cultivated Malvaceae. 1. Hibiscus. Baileya 13: 57-130.

Bovini, M.G., Okano, R.M.C. \& Vieira, M.F. 2001. Malvaceae A. Juss. no Parque Estadual do Rio Doce, Minas Gerais, Brasil. Rodriguesia 52: 17-47.

Coutinho, L.M. 1978. O conceito de Cerrado. Revista Brasileira de Botânica 1: 17-23.

Eiten, G. 1970. A vegetação do Estado de São Paulo. Boletim do Instituto de Botânica 7: 1-87.

Esteves, G.L. 2001. Listagem e nível de proteção das espécies de Fanerógamas do Distrito Federal, Brasil. In: C.E.B. Proença, C.B.R. Munhoz, C.L. Jorge \& M.G.G. Nóbrega (orgs.). Flora do Distrito Federal. EmbrapaCenargen, Brasilia, v.1, pp. 89-359.

Esteves, G.L. 2010. Hibiscus. In: Forzza, R.C. et al. (eds.). Catálogo de Plantas e Fungos do Brasil. Jardim Botânico do Rio de Janeiro, Rio de Janeiro, pp. 1201-1204.

Fryxell, P.A. 1988. Malvaceae of Mexico. Systematic Botany Monographs 25: 1-522.

Fryxell, P.A. 1992. Malvaceae. In: G. Harling \& L. Andersson (eds.). Flora of Ecuador. Berlings, Arlov, n.4, pp. 89-359.

Fryxell, P.A. 1997. The American genera of Malvaceae-II. Brittonia, v.49, pp. 204-269.

Fryxell, P.A. 2001. Talipariti (Malvaceae), a segregate from Hibiscus. Contributions from the University of Michigan Herbarium 23: 225-270.

Gürke, M. 1892. Malvaceae II. In: Flora Brasiliensis. C.F.P. Martius \& A.W. Eichler (eds.). Lipsiae, Frid. Fleischer, v.12, pars. 3, pp. 459-602, tab. 81-114.

Hochreutiner, B.P.G. 1900. Revision du Genre Hibiscus L. Annuaire du Conservatoire et du Jardin Botaniques de Genève 4: 23-191.

Kearney, T.H. 1955. A tentative key to the North American species of Hibiscus L. Leaflets of Western Botany 7: 274-284.

Kearney, T.H. 1957. A tentative key to the South American species of Hibiscus L. Leaflets of Western Botany 8: 161-180. 
Krapovickas A. \& Fryxell A.P. 2004. Las species Sudamericanas de Hibiscus L. Secc. Furcaria DC. (Malvaceae - Hibisceae). Bonplandia 13: 35-115.

Lorenzi, H. \& Souza, H.M. 1995. Plantas Ornamentais no Brasil - arbustivas, herbáceas e trepadeiras. Editora Plantarum, Nova Odessa.

Menzel, M.Y., Fryxell, P.A. \& Wilson, F.D. 1983. Relationships among new world species of Hibiscus section Furcaria (Malvaceae). Brittonia 35: 204-221.

Pfeil, B.E. \& Crisp, M.D. 2005. What to do with Hibiscus? A proposed nomenclatural resolution for a large and well known genus of Malvaceae. Australian Systematic Botany 18: 49-60.

Pfeil, B.E., Brubaker, C.L., Craven, L.A. \& Crisp, M.D. 2002. Phylogeny of Hibiscus and the tribe Hibisceae (Malvaceae) using chloroplast DNA sequences of ndhF and the rpl16 intron. Systematic Botany 27: 333-350.

Poçano, W.L., Carneiro, C.D.R., Bitrichi, C.A., Almeida, F.F.M. \& Prandini, F.L. 1981. Mapa Geomorfológico do Estado de São Paulo. Instituto de Pesquisas Tecnológicas do Estado de São Paulo, São Paulo, v.1, pp. 1-94.

Robyns, A. 1965. Malvaceae. In: Flora of Panama. R.E. Woodson \& R.W. Schery (eds.). Annals of the Missouri Botanical Garden 52: 496-577.

Rodrigo, A.P. 1948. Los Hibiscus de la Flora Argentina (Malvaceae). Revista del Museo de La Plata, Sección Botánica 7:111-152.
Kronka, F.J.N., Matsukuma, C.K. \& Nalon, M.A. 2005. Inventário florestal da vegetação do Estado de São Paulo. Secretaria do Estado de São Paulo, São Paulo, pp. 1-200.

SMA. 1998. Atlas das Unidades de Conservação Ambiental do Estado de São Paulo. Parte I - Litoral. São Paulo, Metalivros: Secretaria do Meio Ambiente, São Paulo, pp. 1-30.

SMA. 1996. Atlas das Unidades de Conservação Ambiental do Estado de São Paulo. Parte II - Interior. São Paulo, Metalivros: Secretaria do Meio Ambiente, São Paulo, pp. 1-30.

Small, R.L. 2004. Phylogeny of Hibiscus sect. Muenchhusia (Malvaceae) based on Chloroplast rpL16 and ndhF, and Nuclear ITS and GBSSI Sequences. Systematic Botany 29: 385-392.

Thiers, B. 2012. Index herbariorum. Disponível em: http:// sciweb.nybg.org/science2/IndexHerbariorum.asp. (acesso em XII-2012).

Veloso, H.P., Rangel, A.L.R. \& Lima, J.C.A. 1991. Classificação da vegetação brasileira, adaptada a um Sistema Universal. Instituto Brasileiro de Geografia e Estatística, Rio de Janeiro.

Wilson, F.D. 1993. Hibiscus section Furcaria (Malvaceae) in islands of the Pacific Basin. Brittonia 45: 275-285. 
